\title{
Experience-Specific Functional Modification of the Dentate Gyrus through Adult Neurogenesis: A Critical Period during an Immature Stage
}

\author{
Ayumu Tashiro, Hiroshi Makino, and Fred H. Gage \\ Laboratory of Genetics, The Salk Institute for Biological Studies, La Jolla, California 92037
}

\begin{abstract}
Neural circuits in the dentate gyrus are continuously modified by adult neurogenesis, whose level is affected by the animal's experience. However, it is not known whether this experience-dependent anatomical modification alters the functional properties of the dentate gyrus. Here, using the expression of immediate early gene products, c-fos and Zif268, as indicators of recently activated neurons, we show that previous exposure to an enriched environment increases the total number of new neurons and the number of new neurons responding to reexposure to the same environment. The increase in the density of activated new neurons occurred specifically in response to exposure to the same environment but not to a different experience. Furthermore, we found that these experience-specific modifications are affected exclusively by previous exposure around the second week after neuronal birth but not later than 3 weeks. Thus, the animal's experience within a critical period during an immature stage of new neurons determines the survival and population response of the new neurons and may affect later neural representation of the experience in the dentate gyrus. This experience-specific functional modification through adult neurogenesis could be a mechanism by which new neurons exert a long-term influence on the function of the dentate gyrus related to learning and memory.
\end{abstract}

Key words: enriched environment; c-fos; zif268; immediate early gene; dentate gyrus; hippocampus; memory; neurogenesis

\section{Introduction}

In contrast to the long-held dogma that neurogenesis is restricted to the developing brain in mammals, it is now accepted that new neurons continue to be added in specific regions of the adult brain, including the dentate gyrus, a subregion of the hippocampus that is crucial in cognitive functions such as learning and memory (Gage, 2000; Gould and Gross, 2002). Large numbers of new granule cells, the principal neuronal type in the dentate gyrus, are produced from dividing cells localized in the subgranular zone. Although many newborn neurons die before they mature, the surviving neurons are functionally integrated into existing neural circuits within 1 month (van Praag et al., 2002; Jessberger and Kempermann, 2003). Accumulating evidence has suggested that these new neurons in the adult dentate gyrus play an impor-

Received Nov. 14, 2006; revised Jan. 30, 2007; accepted Feb. 15, 2007.

This study was supported by the Mind Science Foundation. A.T. was supported by the Research Fellowship from the Uehara Memorial Foundation and is supported by the Japan Society for the Promotion of Science Postdoctoral Fellowship for Research Abroad. F.H.G. is supported by National Institute on Aging, National Institute of Neurological Disorders and Stroke, a contract from Defense Advanced Research Projects Agency, and a grant from the Lookout Fund. We thank M. L. Gage, J. B. Aimone, S. Jessberger, J. K. Leutgeb, S. Leutgeb, M. D. Saxe, and C. Zhao for their comments.

Correspondence should be addressed to Fred H. Gage, 10010 North Torrey Pines Road, La Jolla, CA 92037. E-mail: gage@salk.edu.

A. Tashiro's present address: Center for the Biology of Memory, Norwegian University of Science and Technology, 7489 Trondheim, Norway.

H. Makino's present address: The Watson School of Biological Sciences, Cold Spring Harbor Laboratory, Cold Spring Harbor, NY 11724.

DOI:10.1523/JNEUROSCI.4941-06.2007

Copyright $\odot 2007$ Society for Neuroscience $\quad$ 0270-6474/07/273252-08\$15.00/0 tant role in learning and memory (Shors et al., 2001, 2002; BruelJungerman et al., 2005; Snyder et al., 2005; Winocur et al., 2006).

It has been suggested that the survival of newborn neurons is regulated by animals' experiences. At 4 weeks after 5-bromo-2'deoxyuridine (BrdU) injections, higher numbers of new neurons were found in mice with extensive exposure to an enriched environment (Kempermann et al., 1997), in which environmental complexity presumably provides a larger number of learning opportunities than is provided in standard housing conditions (van Praag et al., 2000). Subsequent studies examining whether learning affects the survival of new neurons reached opposite conclusions (Gould et al., 1999; van Praag et al., 1999). Because the new neurons were labeled at the different timings relative to learning tasks in these studies, the existence of a critical period (Hensch, 2005) for experience-dependent regulation of new neuron survival was postulated (Greenough et al., 1999). In this study, we examine whether a critical period for experience-dependent regulation of new neuron survival exists and, if so, when.

The addition of new neurons leads to the formation of new circuits. Therefore, experience-dependent changes in new neuron survival indicate that the neural circuits in the dentate gyrus are anatomically modified by experience through adult neurogenesis. However, it is not known whether this anatomical modification results in the functional alteration of the dentate gyrus. For example, if the total number of activated neurons (including new and preexisting) was altered because the number of activated new neurons had changed, that would mean that the dentate gyrus was functionally modified by adult neurogenesis. Con- 


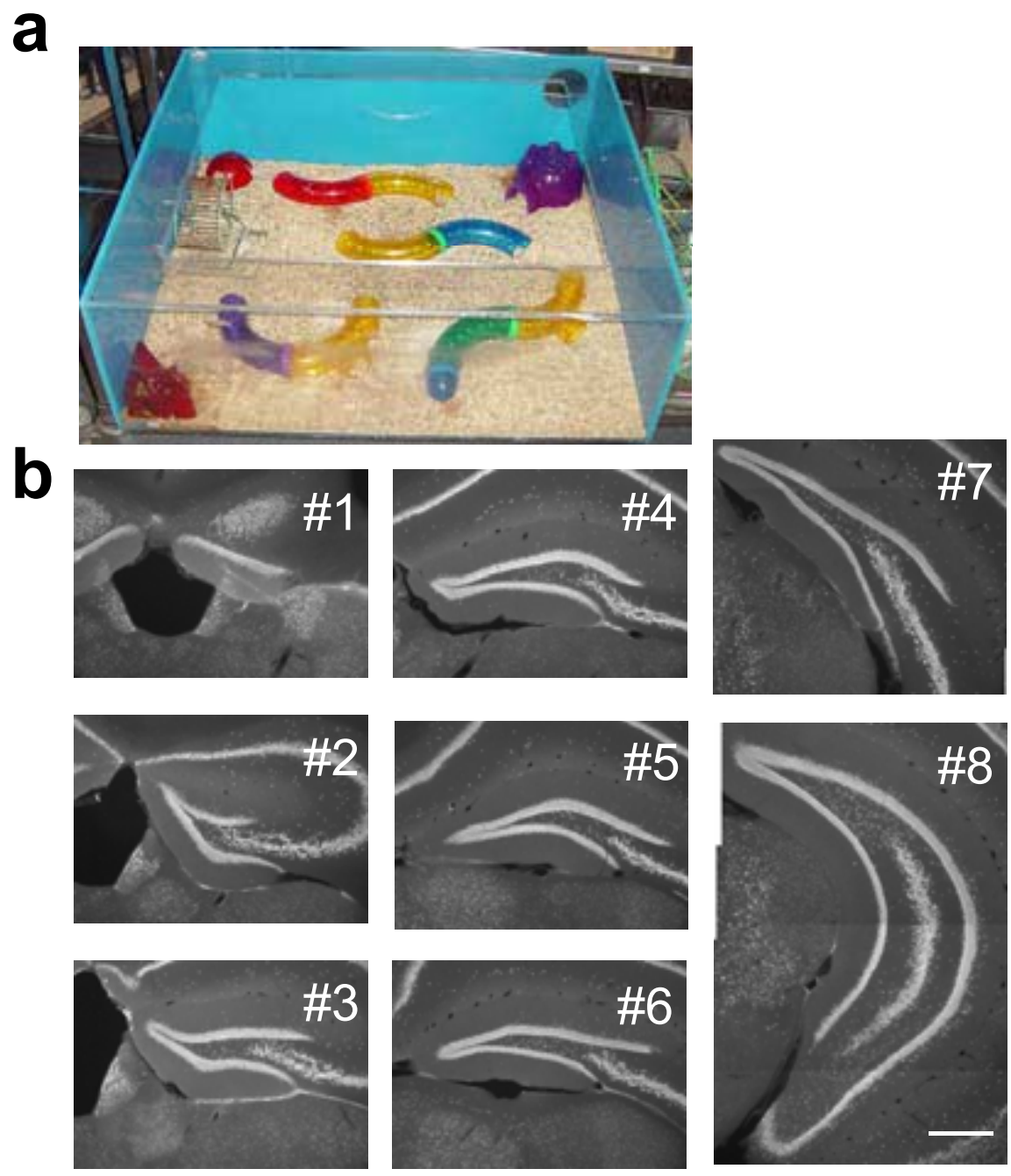

Figure 1. The enriched environment and examined sections from the dentate gyrus. $\boldsymbol{a}, \mathrm{A}$ picture of the enriched cage used in this study. $\boldsymbol{b}$, Representative images of sections used for the analysis from anterior (\#1) to posterior (\#8). The sections were immunostained with anti-NeuN antibody. Scale bar, $100 \mu \mathrm{m}$.

versely, if the number of activated new neurons was not affected, the dentate gyrus might not be functionally altered, despite extensive anatomical modification. Therefore, as the second major issue, we address whether previous exposure to an enriched environment affects the number of new neurons activated by certain later experiences. We examined the expression of immediate early genes, c-fos and Zif268 (Hunt et al., 1987; Saffen et al., 1988; Worley et al., 1993), to determine the activation of new neurons. The expression of these immediate early genes is dependent on synaptic activity (Cole et al., 1989), is required for synaptic plasticity and memory formation (Jones et al., 2001; Fleischmann et al., 2003), is often used as a marker of neuronal activity (Guzowski et al., 2001), and has been used to study new neurons in the adult dentate gyrus (Jessberger and Kempermann, 2003).

\section{Materials and Methods}

Subjects and housing conditions. Eight-week-old mice (C57BL/6) were injected with $\mathrm{BrdU}$ ( $50 \mathrm{mg} / \mathrm{kg}$ body weight) every $12 \mathrm{~h}$ over $4 \mathrm{~d}$ (eight injections) to label newborn neurons. For all of the experiments, 10 mice were housed together in enriched cages, which were large cages with four tunnels, three shelters, and one running wheel (Fig. 1a). When not housed in the enriched cages, they were housed in standard cages with five mice per cage. Immediately before being perfused, some mice were exposed to the enriched cages in group. After $2.5 \mathrm{~h}$, mice were deeply anesthetized with ketamine/xylazine solution and intracardially perfused with $0.9 \% \mathrm{NaCl}$ and then $4 \%$ paraformaldehyde in phosphate buffer. The perfusion procedure took $\sim 10 \mathrm{~min}$ for each mouse, so the exposure time to the enriched cages varied among the mice from 2.5 to $4 \mathrm{~h}$. However, the variability of exposure time was consistent between different groups, and no systematic difference was found with different exposure time.

Water maze. At 6 weeks after the BrdU injections described above, two groups [CW (control) and EW (enriched)] (see Results) of 10 mice were trained in a hidden-platform version of the Morris water maze. The platform was hidden $0.7 \mathrm{~cm}$ below the water surface. Groups of four mice at a time were transferred to the water maze room. A training trial started when each mouse was introduced into a pool $(110 \mathrm{~cm}$ in diameter) and ended when the mouse mounted the platform. The mouse was left on the platform for $30 \mathrm{~s}$ and then transferred back to its home cage. If the mouse did not find the platform by $40 \mathrm{~s}$, it was moved to the platform by an experimenter and left there for $30 \mathrm{~s}$. Single trials for four mice were performed sequentially and then repeated eight times. Eight trials of four mice took $\sim 40 \mathrm{~min}$. Ninety minutes after the end of the last trials, the mice were perfused as described above. Trials were recorded and analyzed by the Ethovision tracking system (Noldus Information Technology, Wageningen, The Netherlands).

Histology. The brains were removed from the skulls and postfixed with $4 \%$ paraformaldehyde overnight, incubated with $30 \%$ sucrose solution in PBS at $4^{\circ} \mathrm{C}$ for $2 \mathrm{~d}$, and cut into 40 $\mu \mathrm{m}$ coronal sections with a microtome. Sections from every $240 \mu \mathrm{m}$ spanning the whole hippocampus (six to eight sections) (Fig. $1 b$, \#1-\#8 from anterior to posterior) were selected and pretreated for BrdU immunostaining with $50 \%$ formamide at $65^{\circ} \mathrm{C}$ for $2 \mathrm{~h}$ and with $2 \mathrm{~N}$

$\mathrm{HCl}$ at $37^{\circ} \mathrm{C}$ for $30 \mathrm{~min}$. Sections were then incubated with primary antibody for $2-3 \mathrm{~d}$ at $4^{\circ} \mathrm{C}$ and then with secondary antibody for $4 \mathrm{~h}$ at room temperature. The primary antibodies used were rabbit anti-c-fos or anti-Zif268 (1:400 dilution; Santa Cruz Biotechnology, Santa Cruz, $\mathrm{CA})$, rat anti-BrdU (1:400; Accurate Chemical and Scientific, Westbury, $\mathrm{NY}$ ), and mouse anti-neuronal-specific nuclear protein (NeuN) antibody (1:400; clone A60 provided by Dr. R. Mullen, Salt Lake City, UT). The secondary antibodies used were Cy3-conjugated anti-rabbit-IgG, FITC-conjugated anti-rat IgG, and $\mathrm{Cy} 5$ or $\mathrm{Cy} 3$-conjugated anti-mouseIgG antibody (1:250; Jackson ImmunoResearch, West Grove, PA). Immunostained sections were mounted on glass slides with anti-fading mounting media.

Microscopy and image analysis. We counted the number of BrdUpositive $\left(\mathrm{BrdU}^{+}\right)$cells in the granule cell layer from all sections (sections 1-8) using a conventional epifluorescence microscope with $40 \times$ oilimmersion lens. To quantify the number of $\mathrm{BrdU}^{+}$cells that coexpressed NeuN, c-fos, or Zif268 immunoreactivity, we used a confocal microscope (Radiance 2100; Bio-Rad, Hercules, CA). For this analysis, sections 3, 4, and 6 [the first experiment (see Figs. 2,3)] or 3 [the second and third experiments (see Figs. 4, 5)] were examined from each mouse. To examine a large number of $\mathrm{BrdU}^{+}$cells precisely but quickly, we examined colocalization in a focal plane with maximal cross-sectional area for $\mathrm{BrdU}^{+}$staining in each cell. Because all antibodies stain the nuclei, the shape of signals from different antibody staining does not match com- 
pletely if the signals are from different nuclei, which have considerable space between them. Therefore, we also carefully checked the shapes of potentially colocalized signals. If there was any uncertainty (i.e., signals are colocalized partially, but the shapes of signals did not completely match between different antibodies), colocalization was examined particularly carefully by taking images from one or two additional focal planes. When colocalization was still difficult to determine, $z$-series were taken. This situation was particularly the case when BrdU signals covered only a small portion of the nucleus, although we used image acquisition setting to visualize weak signals well so that many $\mathrm{BrdU}^{+}$signals covered the whole nuclei. Because of differences in sensitivity, we generally found higher numbers of $\mathrm{BrdU}^{+}$cells with the confocal microscope than with the epifluorescence microscope. To measure the volume of the granule cell layer, images of the NeuNimmunoreactive region in the dentate gyrus were acquired with the epifluorescence microscope. The area of the $\mathrm{NeuN}^{+}$region was measured using Image J Software (NIH) and multiplied by the thickness of sections $(40 \mu \mathrm{m})$ to calculate the volume of the granule cell layer in each section. The density of cells in the dentate gyrus was calculated as the number of cells divided by the volume of the granule cell layer. To measure the proportion of $\mathrm{c}-\mathrm{fos}{ }^{+}$or Zif $268^{+}$ in $\mathrm{NeuN}^{+}$cells, we acquired single confocal images from two to four randomly selected areas from both the suprapyramidal and infrapyramidal blades of all sections (sections 1-8). Colocalization was determined from these images. To calculate an average value of percentage of $\mathrm{c}-f o s^{+}$or $\mathrm{Zif}_{268^{+}}$cells, we used a weighted average with the average volume in each anteroposterior axis (Fig. $1 b, \# 1-\# 8$ ) as a weight.

\section{Results}

The effects of an enriched environment on adult new neurons are restricted to an immature stage of the new neurons In the first experiment, we examined the effects of an enriched environment at different times after BrdU injections. Mice were randomly divided into five groups: a control group and groups 1-4 (10 mice each). The mice were injected with BrdU over $4 \mathrm{~d}$ (eight injections) to label newborn neurons. Ten mice each from groups 1-4 were housed together in enriched cages for 1 week during the first, second, third, or fourth week after the last day of BrdU injections, respectively (Fig. 2a). The control group was always kept in standard cages. Six weeks after the last day of BrdU injections, nine mice from each group were reexposed to the enriched cages, in exactly the same configuration as the first exposure, for 2.5-4 h until the animals were perfused (Fig. 2a), to analyze the expression of c-fos in response to this exposure. The remaining one mouse from each group was killed directly from the standard cages. The brain sections were immunostained with antibodies against BrdU (for progeny of dividing cells at the time of injections), NeuN (for neurons), and c-fos. All of the analyses were performed in the granule cell layer of the dentate gyrus.

First, we selected three sections (sections 3, 4, and 6) from each mouse and measured the density of $\mathrm{BrdU}^{+} / \mathrm{NeuN}^{+}$cells
C

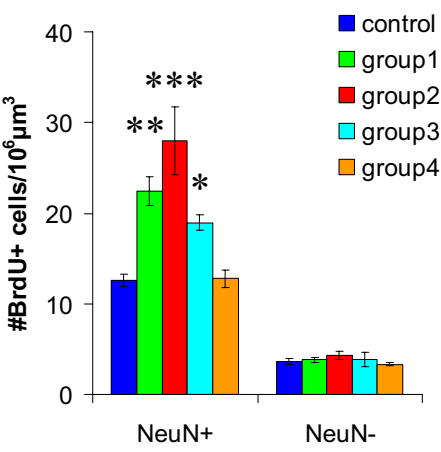

d
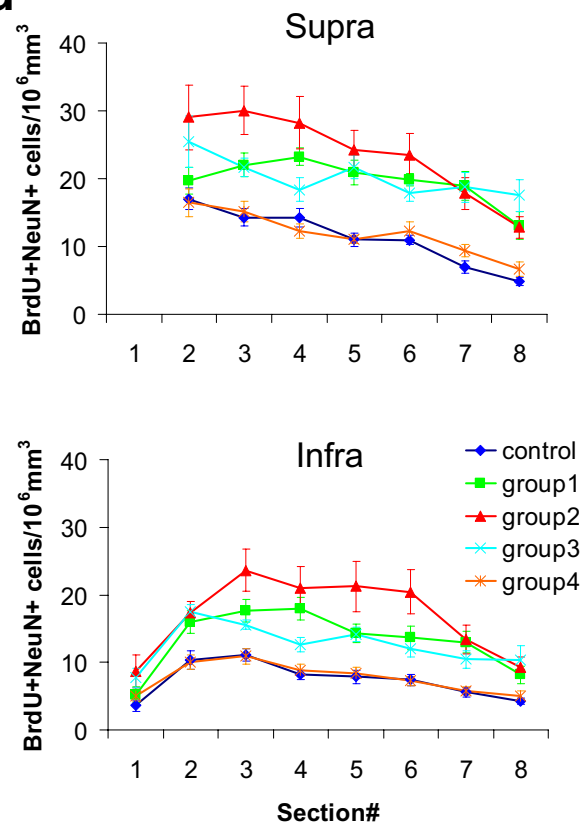

Section\#

Figure 2. One week preexposure to an enriched environment soon after neuronal birth increases the number of new neurons. sections from the control group and group 2. Scale bar, $100 \mu \mathrm{m}$. c, Density of BrdU ${ }^{+} / \mathrm{NeuN}^{+}$and BrdU ${ }^{+} / \mathrm{NeuN}^{-}$cells. $\boldsymbol{d}_{t}$ Estimated density of $\mathrm{BrdU}^{+} / \mathrm{NeuN}^{+}$cells in the suprapyramidal and infrapyramidal blades of each level along the anteroposterior axis. Section numbers correspond to the numbers in Figure $1 b .{ }^{*} p<0.05,{ }^{* *} p<0.005,{ }^{* * *} p<0.0005$ by Fisher's LSD test.

(new neurons). We found that the density significantly increased in groups $1-3$ but not in group $4\left[p<2 \times 10^{-6}\right.$ in ANOVA; $p<$ 0.03 for groups $1-3, p>0.9$ for group 4 against control in Fisher's least significant difference (LSD) test] (Fig. $2 b, c)$. The amount of increase was maximal in group 2, at more than twofold (control, $12.5 \pm 0.6$ cells $/ 10^{6} \mu \mathrm{m}^{3}$; group $2,27.9 \pm 3.7$ cells $\left./ 10^{6} \mu \mathrm{m}^{3}\right)$. In contrast, the density of $\mathrm{BrdU}^{+} / \mathrm{NeuN}$-negative $\left(\mathrm{NeuN}^{-}\right.$) (new non-neuronal) cells was not different between groups $(p>0.6$ in ANOVA) (Fig. 2c). Thus, the increase in density of $\mathrm{BrdU}^{+}$cells was specific to the neuronal population in groups 1-3. To examine the regional differences, we estimated the density of $\mathrm{BrdU}^{+} /$ $\mathrm{NeuN}^{+}$cells in the suprapyramidal and infrapyramidal blades of each anteroposterior level (Fig. $2 b, d, \# 1-\# 8$ ), using the percentage of $\mathrm{NeuN}^{+}$cells in the $\mathrm{BrdU}^{+}$population from the three selected sections (sections 3, 4, and 6) and the density of BrdU ${ }^{+}$ cells measured from each section (sections 1-8). We found that the effects of enrichment were uniformly distributed along the anteroposterior axis in both blades $\left(p<2 \times 10^{-32}\right.$ between groups; $p>0.07$ for group $\times$ section interaction in ANOVA; $p<$ $1 \times 10^{-10}$ in Fisher's LSD test for groups $1-3$ against control) 
a
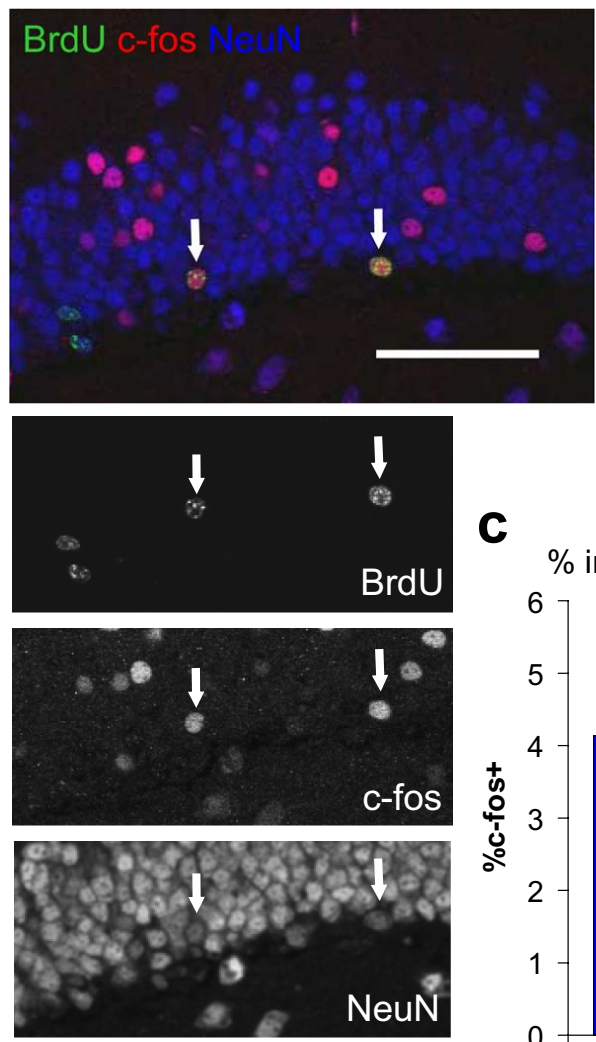
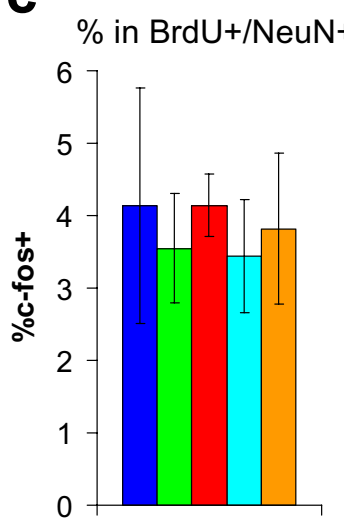

b

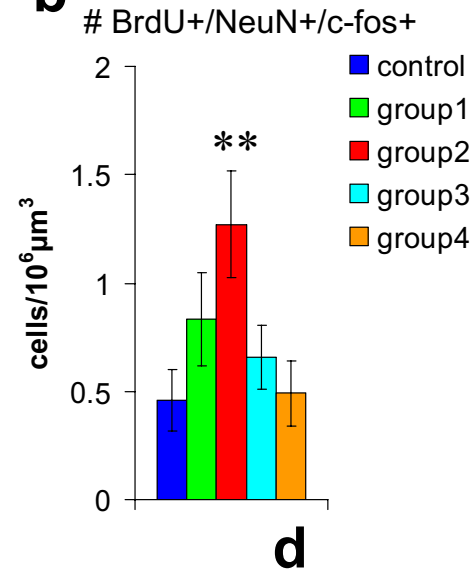

$\%$ in $\mathrm{NeuN}+$

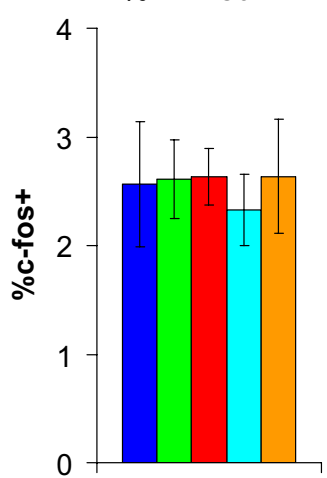

Figure 3. One week preexposure to an enriched environment soon after neuronal birth increases the number of new neurons responding to reexposure to the same environment. $\boldsymbol{a}$, Confocal images of dentate granule cell layer triple immunostained with BrdU (green), c-fos (red), and NeuN (blue). Arrows indicate triple-positive cells. Scale bar, $50 \mu \mathrm{m} . \boldsymbol{b}$, Density of BrdU ${ }^{+} / \mathrm{NeuN}^{+} /$ $c-f_{0 s}{ }^{+}$cells in mice exposed to an enriched environment immediately before being perfused. $c$, Proportions of c-fos ${ }^{+}$in BrdU ${ }^{+} /$ $\mathrm{NeuN}^{+}$cells. $\boldsymbol{d}$, Proportions of $c-$ fos $^{+}{ }^{+}$in NeuN ${ }^{+}$cells. ${ }^{* *} p<0.005$ by Fisher's LSD test.

(Fig. 2d). For example, in group 2, the number of $\mathrm{BrdU}^{+} / \mathrm{NeuN}^{+}$ cells was approximately doubled compared with that of the control group, in both blades of all sections.

Next, we measured the density of $\mathrm{BrdU}^{+} / \mathrm{NeuN}^{+} / \mathrm{c}$-fos ${ }^{+}$cells (activated new neurons) in mice exposed to the enriched environment immediately before being perfused ( $n=9$ mice) (Fig. $3 a)$. We found that the density of $\mathrm{BrdU}^{+} / \mathrm{NeuN}^{+} / \mathrm{c}$-fos ${ }^{+}$cells significantly increased in group 2 by more than twofold (control, $0.46 \pm 0.14$ cells $/ 10^{6} \mu \mathrm{m}^{3}$; group $2,1.27 \pm 0.24$ cells $/ 10^{6} \mu \mathrm{m}^{3}$, $p<0.03$ in ANOVA; $p<0.004$ in Fisher's LSD test) (Fig. $3 b$ ) but not in groups 1,3 , or 4 ( $p>0.15$ against control group in Fisher's LSD test). The proportion of $\mathrm{c}$-fos ${ }^{+}$cells in the $\mathrm{BrdU}^{+} / \mathrm{NeuN}^{+}$ population was not different between groups $(p>0.9$ in ANOVA) (Fig. 3c). We also measured the proportion of $\mathrm{c}-\mathrm{fos}^{+}$ cells in the total $\mathrm{NeuN}^{+}$population (including $\mathrm{BrdU}^{+}$and $\mathrm{BrdU}^{-}$cells) to examine the general activity of neurons in the dentate gyrus. We did not find any significant difference between groups ( $p>0.9$ in ANOVA) (Fig. $3 d$ ).

The increase in the density of $\mathrm{BrdU}^{+} / \mathrm{NeuN}^{+} / \mathrm{c}$-fos ${ }^{+}$triplepositive cells described above can be caused by an increase in the number of $\mathrm{BrdU}^{+} / \mathrm{NeuN}^{+}$cells expressing c-fos in either response to exposure to the enriched environment immediately before the animals were perfused or the basal condition without the exposure. We considered the latter possibility to be unlikely, because virtually no $\mathrm{BrdU}^{+} / \mathrm{NeuN}^{+} / \mathrm{c}$-fos ${ }^{+}$cells were found in mice killed directly from their home cages in the study by Jess- berger and Kempermann (2003). Therefore, only one mouse per group was killed directly from its home cage to confirm no c-fos expression in the basal condition. However, we found a few $\mathrm{BrdU}^{+} /$ $\mathrm{NeuN}^{+} / \mathrm{c}^{-} \mathrm{fos}^{+}$cells in the suprapyramidal blade of a group 1 mouse, although no triple-positive cells were found in any other group. Because of the existence of $\mathrm{BrdU}^{+} / \mathrm{NeuN}^{+} / \mathrm{c}$-fos ${ }^{+}$cells, additional analysis was necessary to statistically examine the difference in c-fos expression in the basal condition. Therefore, we repeated the experiment using a separate group of 10 mice killed directly from their home cages 6 weeks after BrdU injections. Five of these mice were housed in a standard cage for 6 weeks (control group), and the other five mice were exposed to an enriched environment in the second week after BrdU injections (group 2). These mice were the same as those analyzed in the next experiment using Zif268, but different sections were examined with immunostaining for c-fos. Consistent with the previous result, the number of $\mathrm{BrdU}^{+}$/ $\mathrm{NeuN}^{+}$cells was more than two times higher in group 2 than in the control group (control, $14.9 \pm 0.9$ cells $/ 10^{6} \mu \mathrm{m}^{3}$; group 2, $37.1 \pm 1.4$ cells $/ 10^{6} \mu \mathrm{m}^{3} ; p<5 \times$ $10^{-6}$ in two-sided $t$ test). However, the number of $\mathrm{BrdU}^{+} / \mathrm{NeuN}^{+} / \mathrm{c}$-fos ${ }^{+}$was not significantly different between the control group and group 2 (control, $0.05 \pm 0.03$ cells $/ 10^{6} \mu \mathrm{m}^{3}$; group $2,0.08 \pm$ 0.03 cells $/ 10^{6} \mu \mathrm{m}^{3} ; p>0.4$ in two-sided $t$ test). Thus, the $\mathrm{c}$-fos expression level in new neurons was not different between groups in the basal condition without exposure to the enriched environment immediately before the animals were perfused.

\section{Experience-specific increase in the number of activated new neurons}

The increase in the number of activated new neurons that we observed in the first experiment may occur specifically in response to the same environment that they had been exposed to previously or the increase may be a nonspecific response to any experience that activates new neurons. To address this issue, we performed a second experiment to examine the number of activated new neurons responding to a different, recent experience (Fig. 4a). As a different experience, exploration in a different environment may be straightforward. However, single-unit recording from the dentate gyrus in behaving rats showed that many active neurons during spatial exploration in one environment were also active during exploration in a different environment (Leutgeb et al., 2007), indicating that exploration in different environments may not be different enough to generate different patterns of activity in the dentate gyrus. Therefore, we needed to choose a considerably different experience and decided to use the Morris water maze task. Fifty mice were injected with BrdU eight times over $4 \mathrm{~d}$. Twenty-five of these mice were exposed to an enriched environment during the second week after BrdU injections, as had group 2 in the previous experiment. At 6 
weeks after BrdU injections, 10 of these mice were reexposed to the same environment for 2.5-4 h (EE group) until they were perfused, 10 were trained on a hidden-platform version of the water maze task (EW group) and then kept for $90 \mathrm{~min}$ in a dark room until they were perfused, and the remaining five were perfused directly from their home cage (EC group).

The other 25 mice were housed in standard cages until the day they were perfused. As with the EE, EW, and EC groups, 10 of these mice were exposed to the enriched environment (CE group), 10 were trained for the water maze task (CW group), and five were perfused directly from their home cage (CC group). In the water maze training, latency to reach the platform and swim speed were not significantly different between the CW and EW groups $(p>0.3$ in repeated-measures ANOVA) (supplemental Fig. 1a,c, available at www.jneurosci.org as supplemental material), whereas path length was slightly, but significantly, shorter in the EW group than in the CW group $(p<$ 0.04 between groups in repeatedmeasures ANOVA) (supplemental Fig. 1b, available at www.jneurosci.org as supplemental material).

In this experiment, we performed immunostaining for another immediate early gene, Zif268, to examine whether the observed effect in the first experiment can be generalized among different immediate early genes. We analyzed one section (section 3) from each mouse using a confocal microscope (Fig. 4b). Consistent with the previous experiments, the density of $\mathrm{BrdU}^{+}$/ $\mathrm{NeuN}^{+}$was significantly higher in the enriched groups (EE, EW, and EC) than in the control groups (CE, CW, and CC) $(p<2 \times$ $10^{-9}$, ANOVA; $p<2 \times 10^{-5}$ for each pair in Fisher's LSD test) (Fig. 4c). Also consistent with the first experiment, the density of $\mathrm{BrdU}^{+} / \mathrm{NeuN}^{+} / \mathrm{Zif} 268^{+}$cells was higher in the EE group than in the CE group ( $p<0.0002$, ANOVA for six groups; $p<0.004$, Fisher's LSD test) (Fig. 4d). However, the density of $\mathrm{BrdU}^{+}$/ $\mathrm{NeuN}^{+} / \mathrm{Zif268}{ }^{+}$cells was not different between the CW and EW groups or between the CC and EC group ( $p>0.90$, Fisher's LSD test) (Fig. 4d). Thus, the increase in $\mathrm{BrdU}^{+} / \mathrm{NeuN}^{+} / \mathrm{Zif}_{268^{+}}$ cells in those mice preexposed to an enriched environment occurred specifically in response to the experience in the same environment but not to a different experience. From a different point of view, the same data indicate that preexposure to an enriched environment suppresses Zif268 expression in new neurons in response to water maze training, because the density of new neurons was doubled in the EW group but the density of new neurons expressing Zif268 ${ }^{+}$was not different between the CW and EW groups. Nonetheless, the difference in the proportion of Zif268 ${ }^{+}$in the $\mathrm{BrdU}^{+} / \mathrm{NeuN}^{+}$population between the $\mathrm{CW}$ and EW groups as well as between CE and EE or CC and EC did not reach statistical significance $(p<0.005$ in ANOVA; $p>0.17$ in Fisher's LSD test) (Fig. 4e). Proportions of Zif268 ${ }^{+}$in the $\mathrm{NeuN}^{+}$population were not significantly different between the $\mathrm{CE}$ and EE, CW and EW, and CC and EC groups $\left(p<4 \times 10^{-5}\right.$ in ANOVA; $p>0.8$ in Fisher's LSD test) (Fig. $4 f$ ).
C d

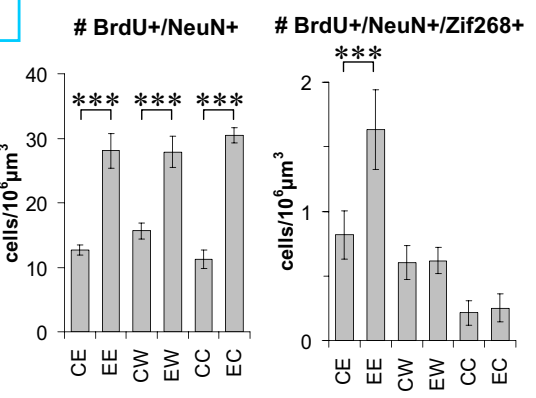

f

d 列

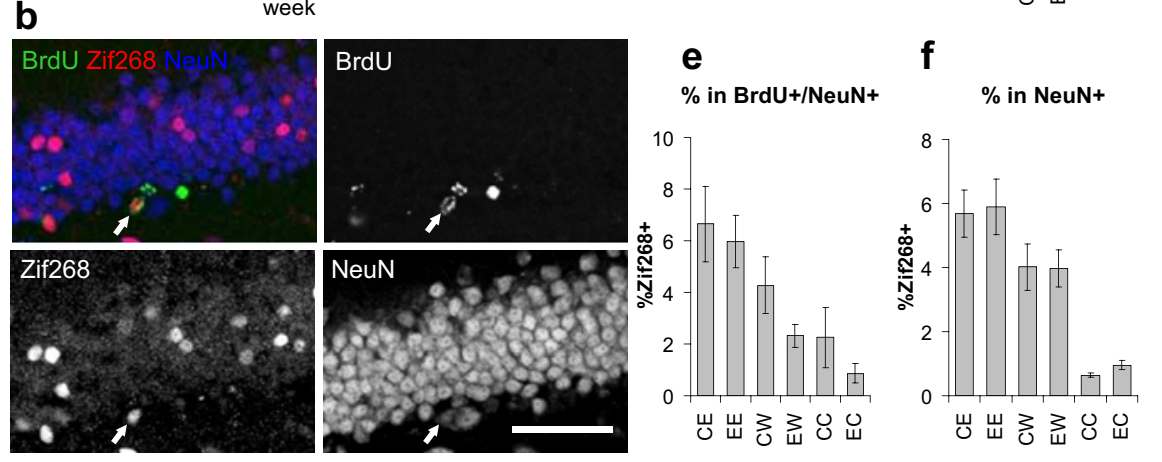

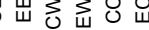

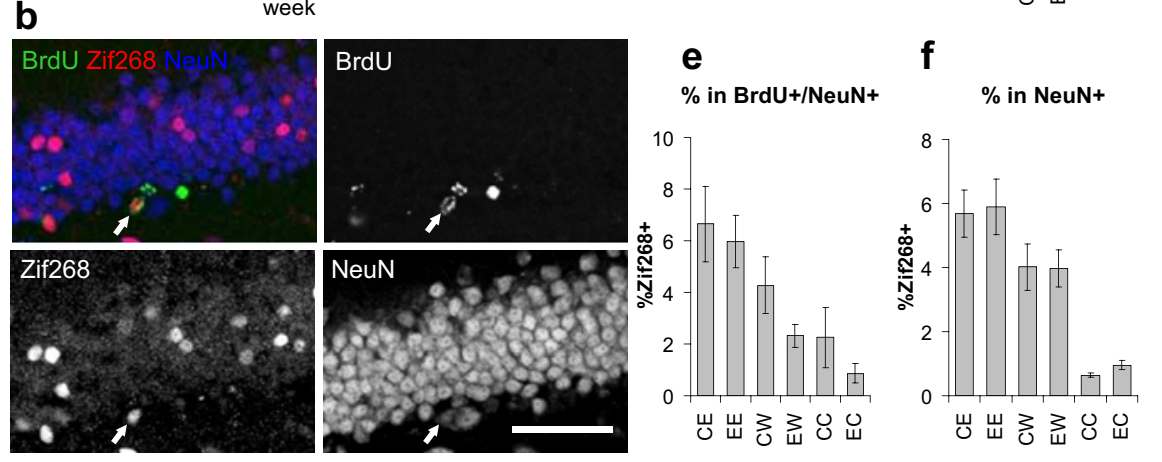

Figure 4. Experience-specific increase in the number of activated new neurons. $\boldsymbol{a}$, Experimental timeline. $\boldsymbol{b}$, Confocal images of $\mu \mathrm{m}$. Density of BrdU ${ }^{+} / \mathrm{NeuN}^{+}$cells (c) and of BrdU ${ }^{+} / \mathrm{NeuN}^{+} / \mathrm{Zif2} 68^{+}$cells (d) in each group. Proportions of Zif268 ${ }^{+}$in $\mathrm{BrdU}^{+} / \mathrm{NeuN}^{+}$cells $(\boldsymbol{e})$ and in NeuN ${ }^{+}$cells $(\boldsymbol{f})$ in each group. ${ }^{* *} p<0.005,{ }^{* * *} p<0.0005$ by Fisher's LSD test.

Long-term survival of mature new neurons is not dependent on continuous exposure to an enriched environment

In the third experiment, we examined whether the long-term survival of new neurons after 4 weeks was dependent on the animal's experience. It has been shown that the number of new neurons in mice housed in standard cages is stable from 4 weeks to at least 11 months after neuronal birth (Kempermann et al., 2003). However, it is not known whether the survival of new neurons rescued by exposure to an enriched environment is similarly stable when the environment is changed after new neurons mature. A similar question has been addressed using a hippocampus-dependent learning task, trace eye-blink conditioning (Leuner et al., 2004). This study showed that the number of new neurons at $60 \mathrm{~d}$ after BrdU injection was higher in conditioned animals than in animals with unpaired stimuli. However, the difference between the conditioned and unpaired groups seemed to be much smaller at $60 \mathrm{~d}$ than at $30 \mathrm{~d}$ after BrdU injections, although comparisons between these numbers from different time points were not analyzed in that study. Therefore, we decided to examine whether continuous exposure to an enriched environment is required for the long-term survival of mature new neurons by comparing the density of new neurons at 4 weeks and at 4 months after the BrdU injections.

The experimental design is summarized in Figure $5 a$. Fifty mice were injected with BrdU eight times over $4 \mathrm{~d}$. Twenty of these mice were housed in an enriched environment for 3 weeks from 8 to $28 \mathrm{~d}$ after BrdU injections. At $28 \mathrm{~d}$ after BrdU injections, 10 of these 20 enriched mice were perfused ( 4 wkENR group). The other 10 were transferred to standard cages at $28 \mathrm{~d}$ after BrdU injections and perfused at 4 months after BrdU injections (4mE-C group). Ten mice were housed in standard cages and perfused at $28 \mathrm{~d}$ after BrdU injections (4wkCTL group). Ten mice were housed in standard cages and perfused at 4 months after BrdU injections (4mCTL group). Ten mice were housed in stan- 
a

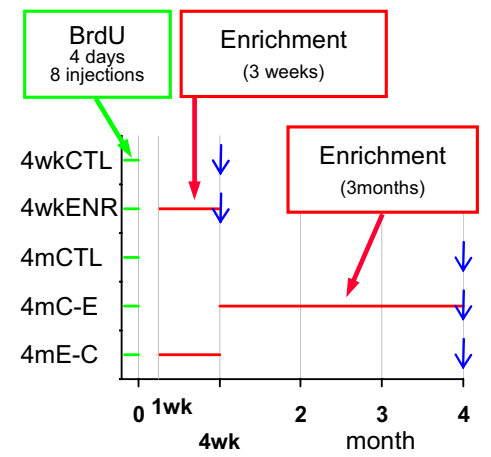

b

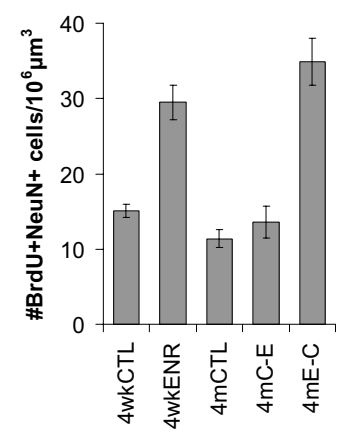

Figure 5. Long-term survival of mature new neurons does not require continuous exposure to the environment that rescued the new neurons during the critical period. $\boldsymbol{a}$, Experimental timeline. $\boldsymbol{b}$, Density of $\mathrm{BrdU}^{+} / \mathrm{NeuN}^{+}$cells in each group.

dard cages until $28 \mathrm{~d}$ after BrdU injections and then housed in an enriched environment until they were perfused at 4 months after BrdU injections (4mC-E group).

We analyzed one section (section 3) from each mouse using the confocal microscope. We found that the densities of $\mathrm{BrdU}^{+}$/ $\mathrm{NeuN}^{+}$cells in the $4 \mathrm{wkENR}$ and $4 \mathrm{mE}-\mathrm{C}$ groups were significantly higher than in the $4 \mathrm{wkCTL}, 4 \mathrm{mCTL}$, and $4 \mathrm{mC}-\mathrm{E}$ groups $\left(p<5 \times 10^{-11}\right.$, ANOVA; $p<0.00002$, Fisher's LSD test) (Fig. $5 b$ ), indicating that exposure to an enriched environment at 1-4 weeks after BrdU injections increased the density of $\mathrm{BrdU}^{+}$/ $\mathrm{NeuN}^{+}$cells, consistent with the previous two experiments. There was no difference in the density of $\mathrm{BrdU}^{+} / \mathrm{NeuN}^{+}$cells between the $4 \mathrm{wkENR}$ and $4 \mathrm{mE}-\mathrm{C}$ groups or among the $4 \mathrm{wkCTL}$, $4 \mathrm{mCTL}$, and $4 \mathrm{mC}$-E groups ( $p>0.07$, Fisher's LSD test) (Fig. $5 b)$. This result indicates that the density of $\mathrm{BrdU}^{+} / \mathrm{NeuN}^{+}$cells was stable regardless of housing conditions from 4 weeks to 4 months after BrdU injections, although we cannot completely exclude the possibility of survival regulation to a much smaller extent. Thus, at least for a majority of new neurons, regardless of whether or not they are rescued by exposure to the enriched environment during the critical period, their long-term survival does not seem to require continuous stimulation from the same environment that rescued the new neurons.

\section{Discussion}

A critical period for the effect of enriched environment on adult new neurons exists during their immature stage

Consistent with a previous study (Kempermann et al., 1997), we found that exposure to an enriched environment increases the number of new neurons. This same study suggested that this increase could be attributed to increased survival, but later studies have indicated that the enriched environment also affects cell proliferation (Kempermann et al., 1998; Kronenberg et al., 2003). The increased proliferation may be particularly relevant in group 1, because large numbers of BrdU-labeled cells continue to divide for at least a few days after BrdU injections (Dayer et al., 2003). However, because the number of new neurons was maximal in group 2, which was exposed to enrichment when proliferation is more limited (Dayer et al., 2003), the major effect of the enriched environment likely resulted from increased survival but not from increased neuronal birth.

Our results indicate that as brief as 1 week of exposure to an enriched environment around the second week after neuronal birth is sufficient to increase both the survival of new neurons and the number of new neurons activated by reexposure to the same

environment. However, neither a 1 week exposure during the fourth week nor long-term exposure after 4 weeks affected these measurements, indicating that a critical period for these effects exists during the first 3 weeks. The fact that exposure during the first and third weeks also substantially increased the number of new neurons suggests that the critical period may be relatively long, although a brief experience during the period may be sufficient to affect adult new neurons. Similar degrees of increase in the number of new neurons observed in extended (Kempermann et al., 1997) and 1 week exposures (Figs. $2 c, 4 c$ ) also support the existence of the critical period.

Although the mechanism of increased survival may not be the same, some forms of hippocampus-dependent learning tasks during this same period were reported to increase the survival of new neurons (Gould et al., 1999; Olariu et al., 2005). A critical period for the survival of new neurons in the olfactory bulb, another region associated with adult neurogenesis, was found during the third and fourth weeks after neuronal birth (Yamaguchi and Mori, 2005).

\section{Experience-specific modification of neuronal activity in the dentate gyrus through adult neurogenesis}

We showed that increased numbers of new neurons responded to reexposure to an enriched environment after preexposure to the enriched environment during a critical period for those new neurons (Figs. 3b, 4d). This increase may result in an increase in the number of activated neurons (including new and preexisting) if the number of activated preexisting new neurons is stable. However, we did not find a significant increase in the proportions of activated neurons in the total neuronal population in mice with preexposure (Figs. $3 d, 4 f$ ). We do not know whether this is because a small increase was masked as a result of large variability in these data or because a decrease in the number of activated preexisting neurons compensated for the increase in the number of activated new neurons. The additional new neurons rescued in mice with the preexposure did not exist in mice without the preexposure, and it is unlikely that they have exactly the same patterns of synaptic connectivity as preexisting neurons that were active in mice without preexposure. Therefore, even if either possibility is true, preexposure to the enriched environment modifies population activity in the whole dentate gyrus by adult neurogenesis, in a way that different identities and/or numbers of neurons are activated.

Importantly, this functional modification caused by previous exposure to an enriched environment is experience specific (Fig. 4d). Preexposure to the enriched environment increased the number of activated new neurons in response to recent exposure to the same environment but not to the water maze training. It is unlikely that this difference was caused by differences in nonspecific features of experience, such as stress level. If that were the case, then new neurons in mice both with and without preexposure should be similarly affected so that differences in the numbers of active new neurons between the CW and EW groups should remain. In addition, the comparable numbers of active new neurons between the CC and EC groups, which likely responded to some experience in the home cages, do not support the possibility that stress caused the observed effects. Thus, previous experience seems to specifically modify population activity in the dentate gyrus responding to an experience similar to a previous one but not to a considerably different one. This experience specificity suggests that the functional modification may reflect a change in the representation of previous experience in the dentate gyrus. 
To get a quantitative sense of this functional modification, we estimated that the proportion of activated new neurons changed from $4 \%$ (without preexposure) to $8 \%$ (with preexposure) of the total number of activated neurons (including old and new) in mice without previous exposure (for the estimation, see supplemental text 1, available at www.jneurosci.org as supplemental material). Thus, a 1 week exposure to an enriched environment might modify subsequent representation of the same environment in the dentate gyrus by changing the number and/or identity of activated neurons by $4 \%$. Furthermore, if this change were cumulative, the dentate circuits could be modified more extensively over a longer period of time. Although these numbers may not be necessarily absolute, as discussed in supplemental text 1 (available at www.jneurosci.org as supplemental material), the present result is the first demonstration of the experiencedependent and -specific functional modification of dentate population activity through adult neurogenesis.

Additionally, the experience-specific regulation of responsiveness suggests changes in the connectivity of new neurons as a population, possibly mediated by the selective survival (Tashiro et al., 2006) and enhanced plasticity (Wang et al., 2000; SchmidtHieber et al., 2004; Zhao et al., 2006) of new neurons (supplemental text 2, available at www.jneurosci.org as supplemental material). In the olfactory bulb, similar odor-specific changes in responsiveness have been described (Magavi et al., 2005).

\section{Implications for the role of adult neurogenesis in learning and memory}

The present results suggest a possible mechanism by which new neurons in the adult dentate gyrus might contribute to learning and memory. Previous experience affects new neurons and modifies the population activity responding to an experience in the same environment but not to a different experience. Thus, the representation of the environment in the dentate gyrus seems to be modified by a relatively brief experience in an experiencespecific manner. This functional modification may enable the dentate gyrus to store information related to the experience. Even 1 month later, this information could be retrieved by the reactivation of new neurons responding to an experience in the same environment. Considering the suggested role of adult new neurons in hippocampus-dependent forms of learning and memory (Shors et al., 2001, 2002; Bruel-Jungerman et al., 2005; Snyder et al., 2005; Winocur et al., 2006), this experience-specific functional modification might be a mechanism by which new neurons play a critical role in information storage related to learning and memory.

An intriguing feature of this functional modification through adult neurogenesis is the existence of a critical period. The functional properties of the dentate gyrus are modified by the animal's experience in a way that new neurons within the critical period are specifically affected, suggesting that new circuits formed by these new neurons may be highly devoted to information related to the experience. Because different populations of adult new neurons are in the critical period at any given time, new circuits formed at different times should code different information depending on the animal's experience during their critical periods. At the same time, a population of new neurons having similar birthdates could associate previously independent information together. One possible function of this mechanism is the encoding of time in new memories, as proposed by Aimone et al. (2006).

Another important feature of the functional modification is its long-term persistence, which suggests a long-lasting func- tional significance of these newly formed circuits. This finding is consistent with reports that, in some forms of hippocampusdependent task, not short-term (Meshi et al., 2006) but longterm memory is dependent on adult neurogenesis (BruelJungerman et al., 2005; Snyder et al., 2005). One possibility is that the long-term existence of newly formed circuits by new neurons directly mediates long-term memory of events that occurred when the new neurons are immature. Another possibility is that adult neurogenesis improves the dentate representation during future experiences that are similar to the previous one. As suggested by the finding that a previous experience led to an experience-specific increase in the number of activated new neurons, the functional incorporation of new neurons may be the insertion of new computational units reflecting the previous experience during the critical period of the new neurons so that representation of the previous experience is specifically improved. This kind of experience-specific adaptive mechanism is probably beneficial for the animal's survival because it is likely that animals encounter situations similar to previously experienced important events.

Although the precise mechanism is still essentially unknown, the present study demonstrates, for the first time, experiencespecific functional modifications of the dentate circuits through adult neurogenesis. Additional investigation is warranted of whether this experience-specific modification has a long-lasting influence on the function of the dentate gyrus and, if so, how information stored in new circuits is involved in long-term cognitive function.

\section{References}

Aimone JB, Wiles J, Gage FH (2006) Potential role for adult neurogenesis in the encoding of time in new memories. Nat Neurosci 9:723-727.

Bruel-Jungerman E, Laroche S, Rampon C (2005) New neurons in the dentate gyrus are involved in the expression of enhanced long-term memory following environmental enrichment. Eur J Neurosci 21:513-521.

Cole AJ, Saffen DW, Baraban JM, Worley PF (1989) Rapid increase of an immediate early gene messenger RNA in hippocampal neurons by synaptic NMDA receptor activation. Nature 340:474-476.

Dayer AG, Ford AA, Cleaver KM, Yassaee M, Cameron HA (2003) Shortterm and long-term survival of new neurons in the rat dentate gyrus. J Comp Neurol 460:563-572.

Fleischmann A, Hvalby O, Jensen V, Strekalova T, Zacher C, Layer LE, Kvello A, Reschke M, Spanagel R, Sprengel R, Wagner EF, Gass P (2003) Impaired long-term memory and NR2A-type NMDA receptor-dependent synaptic plasticity in mice lacking c-Fos in the CNS. J Neurosci 23:9116-9122.

Gage FH (2000) Mammalian neural stem cells. Science 287:1433-1438.

Gould E, Gross CG (2002) Neurogenesis in adult mammals: some progress and problems. J Neurosci 22:619-623.

Gould E, Beylin A, Tanapat P, Reeves A, Shors TJ (1999) Learning enhances adult neurogenesis in the hippocampal formation. Nat Neurosci 2:260-265.

Greenough WT, Cohen NJ, Juraska JM (1999) New neurons in old brains: learning to survive? Nat Neurosci 2:203-205.

Guzowski JF, Setlow B, Wagner EK, McGaugh JL (2001) Experiencedependent gene expression in the rat hippocampus after spatial learning: a comparison of the immediate-early genes Arc, c-fos, and Zif268. J Neurosci 21:5089-5098.

Hensch TK (2005) Critical period plasticity in local cortical circuits. Nat Rev Neurosci 6:877-888.

Hunt SP, Pini A, Evan G (1987) Induction of c-fos-like protein in spinal cord neurons following sensory stimulation. Nature 328:632-634.

Jessberger S, Kempermann G (2003) Adult-born hippocampal neurons mature into activity-dependent responsiveness. Eur J Neurosci 18:2707-2712.

Jones MW, Errington ML, French PJ, Fine A, Bliss TV, Garel S, Charnay P, Bozon B, Laroche S, Davis S (2001) A requirement for the immediate 
early gene Zif268 in the expression of late LTP and long-term memories. Nat Neurosci 4:289-296.

Kempermann G, Kuhn HG, Gage FH (1997) More hippocampal neurons in adult mice living in an enriched environment. Nature 386:493-495.

Kempermann G, Brandon EP, Gage FH (1998) Environmental stimulation of 129/SvJ mice causes increased cell proliferation and neurogenesis in the adult dentate gyrus. Curr Biol 8:939-942.

Kempermann G, Gast D, Kronenberg G, Yamaguchi M, Gage FH (2003) Early determination and long-term persistence of adult-generated new neurons in the hippocampus of mice. Development 130:391-399.

Kronenberg G, Reuter K, Steiner B, Brandt MD, Jessberger S, Yamaguchi M, Kempermann G (2003) Subpopulations of proliferating cells of the adult hippocampus respond differently to physiologic neurogenic stimuli. J Comp Neurol 467:455-463.

Leuner B, Mendolia-Loffredo S, Kozorovitskiy Y, Samburg D, Gould E, Shors TJ (2004) Learning enhances the survival of new neurons beyond the time when the hippocampus is required for memory. J Neurosci 24:7477-7481.

Leutgeb JK, Leutgeb S, Moser MB, Moser EI (2007) Pattern separation in dentate gyrus and CA3 of the hippocampus. Science 315:961-966.

Magavi SS, Mitchell BD, Szentirmai O, Carter BS, Macklis JD (2005) Adultborn and preexisting olfactory granule neurons undergo distinct experience-dependent modifications of their olfactory responses in vivo. J Neurosci 25:10729-10739.

Meshi D, Drew MR, Saxe M, Ansorge MS, David D, Santarelli L, Malapani C, Moore H, Hen R (2006) Hippocampal neurogenesis is not required for behavioral effects of environmental enrichment. Nat Neurosci 9:729-731.

Olariu A, Cleaver KM, Shore LE, Brewer MD, Cameron HA (2005) A natural form of learning can increase and decrease the survival of new neurons in the dentate gyrus. Hippocampus 15:750-762.

Saffen DW, Cole AJ, Worley PF, Christy BA, Ryder K, Baraban JM (1988) Convulsant-induced increase in transcription factor messenger RNAs in rat brain. Proc Natl Acad Sci USA 85:7795-7799.

Schmidt-Hieber C, Jonas P, Bischofberger J (2004) Enhanced synaptic plas- ticity in newly generated granule cells of the adult hippocampus. Nature 429:184-187.

Shors TJ, Miesegaes G, Beylin A, Zhao M, Rydel T, Gould E (2001) Neurogenesis in the adult is involved in the formation of trace memories. Nature 410:372-376.

Shors TJ, Townsend DA, Zhao M, Kozorovitskiy Y, Gould E (2002) Neurogenesis may relate to some but not all types of hippocampal-dependent learning. Hippocampus 12:578-584.

Snyder JS, Hong NS, McDonald RJ, Wojtowicz JM (2005) A role for adult neurogenesis in spatial long-term memory. Neuroscience 130:843-852.

Tashiro A, Sandler VM, Toni N, Zhao C, Gage FH (2006) NMDA-receptormediated, cell-specific integration of new neurons in adult dentate gyrus. Nature 442:929-933.

van Praag H, Kempermann G, Gage FH (1999) Running increases cell proliferation and neurogenesis in the adult mouse dentate gyrus. Nat Neurosci 2:266-270.

van Praag H, Kempermann G, Gage FH (2000) Neural consequences of environmental enrichment. Nat Rev Neurosci 1:191-198.

van Praag H, Schinder AF, Christie BR, Toni N, Palmer TD, Gage FH (2002) Functional neurogenesis in the adult hippocampus. Nature 415:1030-1034.

Wang S, Scott BW, Wojtowicz JM (2000) Heterogenous properties of dentate granule neurons in the adult rat. J Neurobiol 42:248-257.

Winocur G, Wojtowicz JM, Sekeres M, Snyder JS, Wang S (2006) Inhibition of neurogenesis interferes with hippocampus-dependent memory function. Hippocampus 16:296-304.

Worley PF, Bhat RV, Baraban JM, Erickson CA, McNaughton BL, Barnes CA (1993) Thresholds for synaptic activation of transcription factors in hippocampus: correlation with long-term enhancement. J Neurosci 13:4776-4786.

Yamaguchi M, Mori K (2005) Critical period for sensory experiencedependent survival of newly generated granule cells in the adult mouse olfactory bulb. Proc Natl Acad Sci USA 102:9697-9702.

Zhao C, Teng EM, Summers Jr RG, Ming GL, Gage FH (2006) Distinct morphological stages of dentate granule neuron maturation in the adult mouse hippocampus. J Neurosci 26:3-11. 